Ciência Florestal, Santa Maria, v. 26, n. 1, p. 313-320, jan.-mar., 2016

ISSN 0103-9954

\title{
APLICAÇÃO DE AIB E TIPO DE MINIESTACAS NA PRODUÇÃO DE MUDAS DE Handroanthus heptaphyllus Mattos
}

\author{
APPLICATION TYPE AND AIB minicuttings IN SEEDLING PRODUCTION OF Handroanthus \\ heptaphyllus Mattos
}

\begin{abstract}
Taiane Pires de Freitas de Oliveira ${ }^{1}$ Deborah Guerra Barroso ${ }^{2}$ Kelly Ribeiro Lamônica ${ }^{3}$
Giovanna Campos Mamede Weiss de Carvalho ${ }^{4}$
\end{abstract}

\begin{abstract}
RESUMO
O objetivo deste trabalho foi avaliar o efeito do tipo de miniestacas e a necessidade de aplicação de ácido indolbutírico sobre o enraizamento e qualidade das mudas formadas de Handroanthus heptaphyllus. As miniestacas apicais e intermediárias foram obtidas em minijardim multiclonal formado a partir de sementes. As miniestacas foram preparadas com $5 \mathrm{~cm}$ de comprimento, um par de folhas reduzidas a $50 \%$ da área foliar e estaqueadas sem e com AIB na concentração de $8000 \mathrm{mg} \mathrm{L}^{-1}$. As avaliações foram realizadas aos 30 dias, na expedição do setor de enraizamento e aos 120 dias, quando a muda se encontrava formada. $\mathrm{O}$ experimento foi conduzido em delineamento inteiramente casualizado, em esquema fatorial 3 × 2 × 2 (três épocas de coleta, duas concentrações de AIB e duas posições do propágulo), com quatro repetições, sendo 12 miniestacas por repetição. De acordo com os resultados, o AIB não foi necessário para o enraizamento das miniestacas, entretanto, sua utilização promove incremento do número e comprimento de raízes. As miniestacas intermediárias proporcionaram maior massa seca de raízes aos 30 dias após o estaqueamento, e aos 120 dias, maior número de folhas e de raízes. A época de coleta influenciou a qualidade final das mudas. Aquelas produzidas na última coleta (oitavo) apresentaram valores médios inferiores nas características biométricas, exceto para o comprimento e número de raízes de primeira ordem.
\end{abstract}

Palavras-chave: miniestacas; ipê-roxo; propagação vegetativa.

\section{ABSTRACT}

The objective of this study was to evaluate the effect of type of cuttings and the need for application of IBA on rooting and quality of the seedlings formed Handroanthus heptaphyllus. The apical and intermediate cuttings were obtained in multiclonal minigarden formed from seeds. The cuttings were prepared with $5 \mathrm{~cm}$ length, a pair of leaves reduced to $50 \%$ of leaf area without staked and IBA at a concentration of $8000 \mathrm{mg} \mathrm{L}^{-1}$. Evaluations were performed at 30 days, the expedition rooting sector and at 120 days, when the change was in formed. The experiment was conducted in a completely randomized design in a factorial $3 \times 2 \times 2$ (three sampling times, two concentrations of IBA and two positions of propagules), with four replications, with 12 cuttings per replicate. According to the results, the IBA was not necessary for the rooting of the shoots, however, their use promotes an increase in the number and length of roots. The intermediate cuttings showed

1 Engenheira Florestal, MSc., Doutoranda do Programa de Pós-Graduação em Produção Vegetal, Universidade Estadual do Norte Fluminense Darcy Ribeiro, Centro de Ciências e Tecnologias Agropecuárias, Laboratório de Fitotecnia (LFIT), Av. Alberto Lamego, 2000, Parque Califórnia, CEP 28013-602, Campos dos Goytacazes (RJ), Brasil. ibitaiane@hotmail.com

2 Engenheira Agrônoma, Dra $^{\mathrm{a}}$, Professora de Silvicultura, Universidade Estadual do Norte Fluminense Darcy Ribeiro, Centro de Ciências e Tecnologias Agropecuárias, Laboratório de Fitotecnia (LFIT), Av. Alberto Lamego, 2000, Parque Califórnia, CEP 28013-602, Campos dos Goytacazes (RJ), Brasil. deborah@uenf.br

3 Engenheira Agrônoma, $\mathrm{Dr}^{\mathrm{a}}$, Professora de Meio Ambiente, Instituto Fluminense Federal (IFF), Av. Dário Vieira Borges, 235, Parque do Trevo, CEP 28360-000, Bom Jesus do Itabapoana (RJ), Brasil. krlamonica@gmail.com

4 Graduanda em Engenharia Agronômica, Universidade Estadual do Norte Fluminense Darcy Ribeiro, Centro de Ciências e Tecnologias Agropecuárias, Laboratório de Fitotecnia (LFIT), Av. Alberto Lamego, 2000, Parque Califórnia, CEP 28013-602, Campos dos Goytacazes (RJ), Brasil. giovannacampos85@yahoo.com.br

Recebido para publicação em 6/05/2013 e aceito em 22/04/2014

Ci. Fl., v. 26, n. 1, jan.-mar., 2016 
higher dry mass of roots at 30 days after striking, and at 120 days, more leaves and roots. The collection time influenced the final quality of the seedlings. Those produced in the last collection (eighth) had lower mean scores in biometric characteristics, except for the length and number of roots of the first order.

Keywords: minicuttings; ipê-roxo; vegetative propagation.

\section{INTRODUÇÃO}

Dentre as inúmeras espécies nativas, de elevado valor comercial, tem-se o ipê-roxo (Handroanthus heptaphyllus), pertencente à família Bignoniaceae. A espécie é utilizada com frequência na medicina popular (CARVALHO 2003) e também em programas de reflorestamentos e recuperação de áreas degradadas. Apresenta madeira de elevada densidade, durabilidade, resistente e de baixa retratilidade volumétrica (PAULA e ALVES, 2007). Sua propagação comumente tem sido realizada por sementes (CARVALHO, 1994), no entanto, estudos referentes ao processo de produção de mudas são ainda incipientes, para que a produção atenda à demanda.

Para as espécies que apresentam sazonalidade na produção e dificuldade de armazenamento das sementes, a miniestaquia é uma alternativa. Por meio desta técnica é possível a formação de um banco de matrizes em casa de vegetação, com fornecimento de material diversificado para produção de mudas visando à conservação da espécie, além de permitir a seleção de matrizes com características fenotípicas superiores para a produção comercial, como qualidade de fuste para a produção de madeira.

Esta técnica resulta em utilizar propágulo vegetativo com cerca de $5-8 \mathrm{~cm}$ de comprimento, contendo um ou mais pares de folhas seccionadas transversalmente, acerca de um terço de seu comprimento. Dependendo da posição de coleta no ramo, a miniestaca pode ser apical, intermediária ou basal (ALFENAS et al., 2009). O uso de diferentes tipos de miniestacas implica maior aproveitamento das brotações colhidas, aumentando a produtividade do minijardim.

É importante conhecer os fatores que afetam a formação de raízes, pois estão relacionados ao sucesso da produção de mudas via propagação vegetativa (CUNHA et al., 2009). Dentre esses fatores, destacam-se as condições fisiológicas da planta (presença de carboidratos, substâncias nitrogenadas, aminoácidos e compostos fenólicos fornecidos pelas folhas e acumulados na zona de regeneração de raízes), o balanço hormonal e a posição do propágulo na brotação. O ácido indolacético (AIA) constitui a principal auxina endógena das plantas. Geralmente, quanto maior a relação auxina/citocinina maior a formação de raízes, enquanto o contrário facilita a formação de ramos (TAIZ e ZEIGER, 2013). Dentre as várias auxinas sintéticas, as mais utilizadas para o enraizamento de propágulos vegetativos são o ácido indolbutírico (AIB) e o ácido naftalenacético (ANA), apresentando diferentes resultados conforme a espécie, época do ano, concentração e condições ambientais (FACHINELLO et al., 2005).

A posição da estaca utilizada afeta o enraizamento, pois há uma variação no gradiente de juvenilidade em direção à base e no conteúdo de carboidrato ao longo da brotação. Sendo assim, estacas coletadas de diferentes alturas da mesma brotação podem apresentar diferenças na emissão do sistema radicular (FACHINELLO et al., 2005; HARTMANN e KESTER, 1990).

Borges et al. (2011) estudaram o efeito do ácido indolbutírico no enraizamento de miniestacas apicais e intermediárias de clones de Eucalyptus urophylla x E. globulus e E. grandis x E. globulus, coletadas de minicepas propagadas pelo processo de estaquia convencional e conduzidas em sistema de minijardim em canaletão de areia, e verificaram que as miniestacas apicais apresentaram melhor enraizamento, sem influência do hormônio testado. O mesmo comportamento foi observado por Dias et al. (2012) ao avaliarem o efeito do ácido indolbutírico e tipo de miniestacas coletadas de minicepas propagadas via seminal de seis progênies meios-irmãos de angico-vermelho (Anadenanthera macrocarpa (Benth) Brenan).

Entretanto, este comportamento não é comum a todas as espécies. Segundo Silva et al. (2010), o enraizamento de miniestacas de Calophyllum brasiliensis não apresentou diferenças entre as miniestacas apicais e intermediárias coletadas de minijardim formado a partir de sementes.

Sendo assim, o objetivo deste trabalho foi avaliar o efeito do tipo de miniestacas e a necessidade da aplicação de AIB, sobre o enraizamento e qualidade das mudas de Handroanthus heptaphyllus. 


\section{MATERIAIS E MÉTODOS}

O experimento foi implantado em casa de vegetação coberta com plástico de polipropileno $(150 \mu \mathrm{m})$ e sombrite (30\%), localizada na Universidade Estadual do Norte Fluminense Darcy Ribeiro, no município de Campos dos Goytacazes - RJ.

O minijardim multiclonal de Handroanthus heptaphyllus que deu origem aos propágulos utilizados nesta pesquisa foi estabelecido a partir de mudas propagadas por sementes e conduzidos em tubetes de polipropileno, com capacidade de $280 \mathrm{~cm}^{3}$, contendo substrato comercial à base de casca de pinus decomposta, e adubo de liberação lenta (14-14-14), na concentração de $8 \mathrm{~g} \mathrm{Kg}^{-1}$ de substrato. Durante o manejo do minijardim, foram realizadas semanalmente, adubações com $20 \mathrm{~mL}$ de solução nutritiva completa por minicepa durante os dois primeiros meses após a poda apical das mudas. A solução nutritiva utilizada foi a de Bolles Jones (1954), com a seguinte composição: $\mathrm{N}=8 \mathrm{mmol}$ $\mathrm{L}^{-1}\left(37,5 \%\right.$ de $\left.\mathrm{NH}_{4}^{+}\right) ; \mathrm{P}=1 \mathrm{mmol} \mathrm{L} \mathrm{L}^{-1} ; \mathrm{K}=3 \mathrm{mmol}$ $\mathrm{L}^{-1} ; \mathrm{Ca}=2 \mathrm{mmol} \mathrm{L}^{-1} ; \mathrm{Mg}=1,25 \mathrm{mmol} \mathrm{L}^{-1} ; \mathrm{S}=3,75$

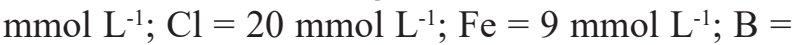
$6,6 \mathrm{mmol} \mathrm{L}^{-1} ; \mathrm{Mn}=10 \mathrm{mmol} \mathrm{L}^{-1} ; \mathrm{Zn}=1 \mathrm{mmol} \mathrm{L}^{-1}$; $\mathrm{Cu}=1 \mathrm{mmol} \mathrm{L}^{-1}$; e $\mathrm{Mo}=0,3 \mathrm{mmol} \mathrm{L}^{-1}$.

Aproximadamente dois meses após o término da aplicação dessa solução, as minicepas apresentaram sintomas de deficiência de nitrogênio. Sendo assim, foi aplicado semanalmente, como fonte do nutriente, $10 \mathrm{~mL}$ de solução de sulfato de amônio $\left(\left(\mathrm{NH}_{4}\right)_{2} \mathrm{SO}_{4}\right)$ por minicepa na concentração de $8 \mathrm{~g} \mathrm{~L}^{-1}$.

As miniestacas apicais e intermediárias utilizadas nesse estudo foram provenientes de três épocas de coleta de brotações aos oito, nove e onze meses após a poda apical, sendo as duas primeiras na primavera e a última no verão.

Previamente ao estaqueamento, as miniestacas foram preparadas com aproximadamente $5 \mathrm{~cm}$, contendo um par de folhas reduzidas em $50 \%$ de sua área foliar. No intuito de verificar se o comportamento encontrado por Freitas (2012) no enraizamento das miniestacas das primeiras épocas de coletas de brotação iria se manter, metade das miniestacas apicais e intermediárias tiveram sua base mergulhada em regulador de crescimento AIB na concentração de $8000 \mathrm{mg} \mathrm{L}^{-1}$ e a outra metade estaqueada sem aplicação do mesmo.

Posteriormente, as miniestacas foram alocadas em tubetes cônicos de $180 \mathrm{~cm}^{3}$, contendo substrato comercial à base de casca de pinus decomposta e adubo de liberação lenta (14-1414) na concentração de $8 \mathrm{~g} \mathrm{Kg}^{-1}$ de substrato, permanecendo em câmara de nebulização com cobertura plástica de polipropileno de $150 \mu \mathrm{m}$, sob nebulização intermitente, com pulverizações de 15 segundos, a cada 15 minutos, mantendo-se assim, o controle da umidade até a emissão do sistema radicular.

Aos 30 dias após o estaqueamento, na expedição do setor de enraizamento, foi avaliada a sobrevivência das miniestacas, considerando mortas aquelas que se apresentavam desprovidas de folhas, com coloração escura e desidratadas, sendo então descartadas. Em quatro mudas por parcela foram avaliados o percentual de enraizamento, número de raízes adventícias primárias (originadas da base das miniestacas) e adventícias laterais de segunda ordem (originadas a partir das primárias), comprimento das raízes primárias e massa seca do sistema radicular. Para isso, foi retirado todo o excesso de substrato do sistema radicular com água, usando peneiras para reter as raízes. $\mathrm{O}$ comprimento das raízes foi medido com auxílio de uma régua e para avaliar a massa seca, as raízes foram acondicionadas em sacos de papel, devidamente identificados, em estufa de circulação forçada a $65^{\circ} \mathrm{C} \pm 2^{\circ} \mathrm{C}$, por 72 horas, para posterior pesagem em balança analítica.

O restante das mudas foi mantido em casa de vegetação, para crescimento e aclimatização. Nessa fase, as mudas foram irrigadas duas vezes ao dia e não receberam adubação, além da oferecida como liberação lenta durante o preparo do substrato. Ao final de 120 dias, estas foram avaliadas quanto à altura e ao diâmetro. Em quatro mudas por parcela foram avaliados o número de folhas, a área foliar, a massa seca da parte aérea e do sistema radicular, o número e o comprimento das raízes adventícias primárias. Para medição da altura e diâmetro, foram utilizados respectivamente, uma régua e um paquímetro digital. A área foliar foi determinada pelo medidor de área foliar eletrônico de bancada (LI-3000, LI-COR Inc.). As demais variáveis foram avaliadas seguindo os mesmos procedimentos descritos no parágrafo anterior.

$\mathrm{O}$ experimento foi conduzido em delineamento inteiramente casualizado, em esquema fatorial $3 \times 2 \times 2$ (três coletas de brotações, duas concentrações de AIB e duas tipos de miniestacas), com quatro repetições, compostas por 12 miniestacas por repetição.

Os dados foram submetidos aos testes de 
TABELA 1: Sobrevivência, número de raízes adventícias primárias (NRAP), número de raízes adventícias laterais de segunda ordem (NRASO), comprimento de raízes primárias (CRP), massa seca das raízes (MSR) e enraizamento (ENR) em miniestacas de Handroanthus heptaphyllus, aos 30 dias após o estaqueamento, em relação à aplicação de AIB, tipo da miniestaca e da época de coleta após a poda apical.

TABLE 1: Average survival rate, number of primary adventitious roots (NPAR), number of lateral adventitious roots of second order (NARSO), length of primary roots (LPR), dry weight of roots (DWR) and average rooting rate (ARR) in cuttings of Handroanthus heptaphyllus, the 30 days after staking, regarding the application of IBA, minicuttings type and time of collection after tip pruning.

\begin{tabular}{|c|c|c|c|c|c|c|c|c|c|c|}
\hline \multirow{4}{*}{ Épocas de coleta } & \multicolumn{5}{|c|}{ Sobrevivência (\%) } & \multicolumn{5}{|c|}{ NRAP } \\
\hline & \multicolumn{4}{|c|}{ AIB $\left(\mathrm{mg} \mathrm{L}^{-1}\right)$} & \multirow{3}{*}{ Média } & \multicolumn{4}{|c|}{ AIB $\left(\mathrm{mg} \mathrm{L}^{-1}\right)$} & \multirow{3}{*}{ Média } \\
\hline & \multicolumn{2}{|c|}{0} & \multicolumn{2}{|c|}{8000} & & \multicolumn{2}{|c|}{0} & \multicolumn{2}{|c|}{8000} & \\
\hline & Apical & Inter. & Apical & Inter. & & Apical & Inter. & Apical & Inter. & \\
\hline $5\left(8^{*}\right)$ & 83,3 & 85,4 & 85,4 & 77,1 & $82,8 \mathrm{a}$ & 2,8 & 4,3 & 4,9 & 4,3 & $4,1 \mathrm{a}$ \\
\hline $6(9 *)$ & 93,8 & 93,8 & 81,3 & 91,7 & $90,1 \mathrm{a}$ & 3,6 & 2,2 & 5,4 & 3,6 & $3,7 \mathrm{a}$ \\
\hline $8(11 *)$ & 81,3 & 93,7 & 85,4 & 89,6 & $87,4 \mathrm{a}$ & 2,5 & 2,7 & 4,4 & 5,7 & $3,8 \mathrm{a}$ \\
\hline \multirow{2}{*}{ Média } & $86,1 \mathrm{~A}$ & $90,9 \mathrm{~A}$ & $84,0 \mathrm{~A}$ & $86,1 \mathrm{~A}$ & & $3,0 \mathrm{~A}$ & $3,0 \mathrm{~A}$ & $4,9 \mathrm{~A}$ & $4,5 \mathrm{~A}$ & \\
\hline & \multicolumn{2}{|c|}{$88,5 \mathrm{~A}$} & \multicolumn{2}{|c|}{$85,0 \mathrm{~A}$} & & \multicolumn{2}{|c|}{$3,0 \mathrm{~B}$} & \multicolumn{2}{|c|}{$4,7 \mathrm{~A}$} & \\
\hline \multirow[t]{2}{*}{ CV (\%) } & \multicolumn{4}{|c|}{6,11} & \multicolumn{6}{|c|}{29,4} \\
\hline & \multicolumn{4}{|c|}{ NRASO } & \multicolumn{6}{|c|}{$\mathrm{CRP}(\mathrm{cm})$} \\
\hline $5(8 *)$ & 26,1 & 26,7 & 36,2 & 26,8 & $29,0 \mathrm{a}$ & 13,9 & 22,5 & 27,7 & 22,1 & $21,5 \mathrm{a}$ \\
\hline $6(9 *)$ & 28,0 & 10,1 & 28,9 & 29,4 & $24,1 \mathrm{a}$ & 18,8 & 8,5 & 20,3 & 22,8 & $17,6 \mathrm{a}$ \\
\hline $8(11 *)$ & 24,4 & 24,8 & 31,2 & 36,2 & $29,1 \mathrm{a}$ & 16,7 & 18,0 & 25,4 & 37,8 & $24,5 \mathrm{a}$ \\
\hline \multirow{2}{*}{ Média } & $26,1 \mathrm{~A}$ & $20,5 \mathrm{~A}$ & $32,1 \mathrm{~A}$ & $30,8 \mathrm{~A}$ & & $16,5 \mathrm{~A}$ & $16,3 \mathrm{~A}$ & $24,5 \mathrm{~A}$ & $27,6 \mathrm{~A}$ & \\
\hline & \multicolumn{2}{|c|}{$23,3 \mathrm{~B}$} & \multicolumn{2}{|c|}{$31,5 \mathrm{~A}$} & & \multicolumn{2}{|c|}{16,4 B } & \multicolumn{2}{|c|}{$26,0 \mathrm{~A}$} & \\
\hline \multirow[t]{2}{*}{ CV (\%) } & \multicolumn{4}{|c|}{33,4} & \multicolumn{6}{|c|}{24,2} \\
\hline & \multicolumn{4}{|c|}{ MSR (g) } & \multicolumn{6}{|c|}{ ENR (\%) } \\
\hline $5(8 *)$ & 0,036 & 0,061 & 0,055 & 0,069 & $0,055 \mathrm{ab}$ & 50,0 & 62,5 & 87,5 & 62,5 & $65,6 a$ \\
\hline $6\left(9^{*}\right)$ & 0,036 & 0,023 & 0,037 & 0,056 & $0,038 b$ & 62,5 & 87,5 & 50,0 & 62,5 & $65,6 \mathrm{a}$ \\
\hline $8\left(11^{*}\right)$ & 0,048 & 0,093 & 0,062 & 0,086 & $0,072 \mathrm{a}$ & 50,0 & 75,0 & 56,3 & 56,3 & $59,4 \mathrm{a}$ \\
\hline \multirow{2}{*}{ Média } & $0,039 \mathrm{~B}$ & $0,059 \mathrm{~A}$ & $0,051 \mathrm{~B}$ & $0,070 \mathrm{~A}$ & & $54,2 \mathrm{~A}$ & $75,0 \mathrm{~A}$ & $64,6 \mathrm{~A}$ & $60,4 \mathrm{~A}$ & \\
\hline & 0,04 & $9 \mathrm{~A}$ & 0,06 & $1 \mathrm{~A}$ & & 64,6 & & 62, & & \\
\hline
\end{tabular}

Em que: (*)meses após a poda apical das mudas; $\mathrm{CV}=$ coeficiente de variação, em \%; Médias seguidas da mesma letra maiúscula na linha e minúscula na coluna não diferem entre si pelo teste de Tukey $(5 \%)$.

Cochran e Lilliefors a 5\% de probabilidade de erro. Quando não apresentaram homocedasticidade e distribuição normal, foi realizada transformação. Os resultados dos dados de contagens foram transformados em $\log (\mathrm{x}+1)$ antes de realizar as análises de variância. As diferenças entre as médias foram comparadas pelo teste de Tukey $(5 \%$ de probabilidade de erro) (ZIMMERMANN, 2004).

\section{RESULTADOS E DISCUSSÕES}

Na expedição do setor de enraizamento das miniestacas coletadas aos oito, nove e onze meses após a poda apical não foi observada interação entre os fatores testados (épocas de coletas, aplicação de AIB e tipo de miniestaca), sobre as características mensuradas (Tabela 1).

Para todos os tratamentos testados, a sobrevivência foi superior a $84 \%$, não havendo diferença entre eles. Esse resultado demonstra que a média de temperatura $\left(23,1^{\circ} \mathrm{C}\right)$ e umidade relativa $(92,1 \%)$ da câmara de nebulização durante a condução do experimento se encontrava em condições adequadas para a espécie. Apesar disso, a alta sobrevivência das miniestacas não é garantia de sucesso no enraizamento. 
Em diferentes tipos de miniestacas (caulinar apical, caulinar intermediário, foliar com e sem cruzeta) de Toona ciliata, Moraes et al. (2014) também não verificou diferença na sobrevivência em ambiente nebulizado. O autor observou aos 20 dias, sobrevivência acima de $96 \%$ em todos os tratamentos. Assim como Borges et al. (2011) que, ao avaliarem entre outras variáveis, a sobrevivência de miniestacas apicais e intermediárias de 11 clones de Eucalyptus grandis x E. globulus, submetidos a três concentrações de AIB $\left(0,2000\right.$ e $\left.4000 \mathrm{mg} \mathrm{L}^{-1}\right)$ não encontraram diferença entre os tratamentos. Ao final de 30 dias, na expedição do setor de enraizamento a sobrevivência foi superior a $91 \%$.

$\mathrm{O}$ número e o comprimento de raízes adventícias primárias e o número de raízes adventícias laterais de segunda ordem foram influenciados pela aplicação de AIB, com valores superiores, respectivamente 4,$7 ; 26 \mathrm{~cm}$ e 31,5 , quando as miniestacas foram submetidas a 8000 $m g \mathrm{~L}^{-1}$ desse hormônio. Já a massa seca das raízes foi influenciada apenas pela época de coleta e tipo de miniestacas, em que a oitava coleta, aos onze meses após a poda apical, bem como as miniestacas intermediárias apresentaram maior valor (Tabela 1).

Esses resultados corroboram os de Ferreira et al (2012), que também não encontrou diferença para o número e comprimento médio das raízes ao utilizar miniestacas apicais, intermediárias e basais de cedro-australiano (Toona ciliata). Já Moraes et al. (2014) observou que miniestacas apicais de cedro-australiano obtiveram maiores comprimento e massa seca de raízes com crescimento mais acelerado em relação às miniestacas intermediárias. Para a mesma espécie, esses autores encontraram resultados diferentes. Isso pode ser reflexo da utilização de diferentes materiais genéticos, visto que ambos trabalharam com minicepas de origem seminal.

$O$ percentual de enraizamento das miniestacas não foi influenciado por nenhum dos tratamentos testados. Então se pode inferir que o grau de juvenilidade e o balanço hormonal interno dos propágulos utilizados foram eficientes em estimular a emissão das raízes.

Diversos estudos têm sido desenvolvidos utilizando a miniestaquia como técnica de propagação, e grandes variações nas taxas de enraizamento são encontradas.

Hernández et al. (2012) obtiveram melhores resultados de enraizamento (acima de 90\%) nas estacas apicais de Piptadenia gonoacantha, independente das doses de AIB testadas $(0,2000$ e $\left.6000 \mathrm{mg} \mathrm{L}^{-1}\right)$. Já as miniestacas intermediárias sem aplicação do hormônio proporcionou $65 \%$ de enraizamento.

Para o jequitibá-rosa (Cariniana estrellensis), Castro (2011) também verificou que as estacas apicais, coletadas de jardim clonal de origem seminal apresentaram maior potencial de enraizamento em relação às intermediárias, além de proporcionar às mudas maior massa seca da parte aérea e do sistema radicular. Os resultados obtidos também não evidenciaram a necessidade da aplicação de AIB na propagação vegetativa dessa espécie.

Por sua vez, em Anadenanthera macrocarpa, Dias et al. (2012) estudaram o enraizamento de dois tipos de miniestaca (apicais e intermediárias), submetidas a quatro concentrações de AIB $(0 ; 2000$; 4000 e $6000 \mathrm{mg} \mathrm{L}^{-1}$ ), em seis progênies e verificaram que as concentrações de AIB não influenciaram nas variáveis analisadas. Entretanto, os autores observaram que independentemente da progênie, as miniestacas apicais apresentaram médias superiores às miniestacas intermediárias para a sobrevivência, número de raízes, massa seca da parte aérea e da raiz.

Silva et al. (2010) encontraram resultados contrários aos observados no presente estudo ao avaliarem o percentual de enraizamento em miniestacas apicais e intermediárias de Calophyllum brasiliensis, tratadas com diferentes concentrações de $\operatorname{AIB}\left(0,2000,4000\right.$ e $\left.8000 \mathrm{mg} \mathrm{L}^{-1}\right)$. Os autores verificaram que o índice de enraizamento foi influenciado apenas pelas miniestacas apicais tratadas com $8000 \mathrm{mg} \mathrm{L}^{-1}$, as quais mostraram uma pequena queda na porcentagem de enraizamento.

Figueirêdo et al. (2013) estudaram o enraizamento de miniestacas de Annona muricata L., utilizando-se estacas apicais e subapicais herbáceas coletadas em plantas cultivadas no campo e em casa de vegetação e verificaram que a miniestaquia pode ser utilizada como método eficiente de propagação utilizando-se estacas apicais oriundas de plantas-matrizes cultivadas em campo e subapicais de plantas-matrizes mantidas no campo e no viveiro. A aplicação de $6000 \mathrm{mg} \mathrm{kg}^{-1}$ de AIB não apresenta efeito no enraizamento de miniestacas de gravioleira.

A qualidade das mudas formadas foi avaliada ao final de 120 dias. Não foi observada interação entre os fatores (épocas de coletas, concentrações de AIB e tipo de miniestaca), sobre 
TABELA 2: Número de folhas (NF), altura (H), diâmetro do coleto (DAC), área foliar (AF), massa seca da parte aérea (MSPA), massa seca das raízes (MSR), número de raízes adventícias primárias (NRAP) e comprimento de raízes primárias (CRP) em miniestacas de Handroanthus heptaphyllus, aos 120 dias após o estaqueamento, em relação à aplicação de AIB, tipo de miniestaca e da época de coleta após a poda apical.

TABLE 2: Number of sheets (NS), height (H), diameter (DAC), leaf area (LA), shoot dry mass (SDM) root dry mass (RDM), number of primary adventitious roots (NPAR) and length of primary roots (LPR) in cuttings of Handroanthus heptaphyllus 120 days after striking, depending on the application of IBA, minicuttings type and time of collection after tip pruning.

\begin{tabular}{|c|c|c|c|c|c|c|c|c|c|c|}
\hline \multirow{4}{*}{ Épocas de coleta } & \multicolumn{4}{|c|}{ NF } & & \multicolumn{5}{|c|}{ MSPA (g) } \\
\hline & \multicolumn{4}{|c|}{$\operatorname{AIB}\left(\mathrm{mg} \mathrm{L}^{-1}\right)$} & \multirow{3}{*}{ Média } & \multicolumn{4}{|c|}{$\operatorname{AIB}\left(\mathrm{mg} \mathrm{L}^{-1}\right)$} & \multirow{3}{*}{ Média } \\
\hline & \multicolumn{2}{|c|}{0} & \multicolumn{2}{|c|}{8000} & & \multicolumn{2}{|c|}{0} & \multicolumn{2}{|c|}{8000} & \\
\hline & Apical & Inter. & Apical & Inter. & & Apical & Inter. & Apical & Inter. & \\
\hline $5\left(8^{*}\right)$ & 13,8 & 15,9 & 14,1 & 15,8 & $14,9 \mathrm{a}$ & 3,596 & 3,439 & 3,801 & 3,598 & $3,609 \mathrm{a}$ \\
\hline $6(9 *)$ & 15,7 & 15,8 & 16,4 & 14,9 & $15,8 \mathrm{a}$ & 4,251 & 3,496 & 4,158 & 3,558 & $3,866 \mathrm{a}$ \\
\hline $8(11 *)$ & 9,0 & 10,5 & 12,2 & 10,5 & $10,5 b$ & 1,699 & 2,279 & 2,627 & 2,324 & $2,232 b$ \\
\hline \multirow{2}{*}{ Média } & $12,8 \mathrm{~B}$ & $14,1 \mathrm{~A}$ & $14,2 \mathrm{~A}$ & $13,7 \mathrm{~A}$ & & $3,182 \mathrm{~A}$ & $3,071 \mathrm{~A}$ & $3,529 \mathrm{~A}$ & $3,160 \mathrm{~A}$ & \\
\hline & \multicolumn{2}{|c|}{$13,4 \mathrm{~A}$} & \multicolumn{2}{|c|}{$14,0 \mathrm{~A}$} & & \multicolumn{2}{|c|}{$3,127 \mathrm{~A}$} & \multicolumn{2}{|c|}{$3,344 \mathrm{~A}$} & \\
\hline \multirow[t]{4}{*}{ CV (\%) } & \multicolumn{4}{|c|}{2,4} & \multicolumn{6}{|c|}{19,0} \\
\hline & \multicolumn{4}{|c|}{$\mathrm{H}(\mathrm{cm})$} & & \multicolumn{4}{|c|}{$\operatorname{MSR}(\mathrm{g})$} & \\
\hline & \multicolumn{2}{|c|}{0} & \multicolumn{2}{|c|}{8000} & & \multicolumn{2}{|c|}{0} & \multicolumn{2}{|c|}{8000} & \\
\hline & Apical & Inter. & Apical & Inter. & & Apical & Inter. & Apical & Inter. & \\
\hline $5\left(8^{*}\right)$ & 15,3 & 14,5 & 17,3 & 17,3 & $16,1 \mathrm{~b}$ & 1,320 & 1,127 & 1,521 & 1,295 & $1,316 \mathrm{a}$ \\
\hline $6(9 *)$ & 23,8 & 22,6 & 23,6 & 25,8 & $23,9 \mathrm{a}$ & 1,673 & 1,401 & 1,618 & 1,319 & $1,503 \mathrm{a}$ \\
\hline $8(11 *)$ & 9,6 & 14,5 & 10,9 & 13,3 & $12,1 \mathrm{c}$ & 0,671 & 0,815 & 1,202 & 1,078 & $0,942 \mathrm{~b}$ \\
\hline \multirow{2}{*}{ Média } & $16,2 \mathrm{~A}$ & $17,2 \mathrm{~A}$ & $17,3 \mathrm{~A}$ & $18,8 \mathrm{~A}$ & & $1,221 \mathrm{~A}$ & $1,114 \mathrm{~A}$ & $1,447 \mathrm{~A}$ & $1,231 \mathrm{~A}$ & \\
\hline & & & $18,($ & & & & $58 \mathrm{~A}$ & & $39 \mathrm{~A}$ & \\
\hline CV (\%) & & & & & & & 3 &, 6 & & \\
\hline & & DAC & $(\mathrm{mm})$ & & & & & $\mathrm{AP}$ & & \\
\hline & & & 80 & & & & ) & & 00 & \\
\hline & Apical & Inter. & Apical & Inter. & & Apical & Inter. & Apical & Inter. & \\
\hline $5(8 *)$ & 5,4 & 5,5 & 5,7 & 5,7 & $5,6 \mathrm{a}$ & 6,2 & 7,8 & 8,0 & 11,3 & $8,3 \mathrm{a}$ \\
\hline $6(9 *)$ & 5,0 & 5,1 & 4,8 & 4,8 & $4,9 \mathrm{~b}$ & 3,5 & 6,7 & 8,2 & 7,1 & $6,4 b$ \\
\hline $8(11 *)$ & 4,5 & 4,7 & 4,9 & 5,1 & $4,8 \mathrm{~b}$ & 8,7 & 9,1 & 8,6 & 10,3 & $9,2 \mathrm{a}$ \\
\hline Média & $4,9 \mathrm{~A}$ & $5,1 \mathrm{~A}$ & $5,1 \mathrm{~A}$ & $5,2 \mathrm{~A}$ & & $6,1 \mathrm{~B}$ & $7,8 \mathrm{~A}$ & $8,2 \mathrm{~B}$ & $9,6 \mathrm{~A}$ & \\
\hline Miedia & & & 5,1 & & & & $\mathrm{~B}$ & & $9 \mathrm{~A}$ & \\
\hline CV (\%) & & & & & & & & 3,5 & & \\
\hline & & $\mathrm{AF}$ & $\left.\mathrm{cm}^{2}\right)$ & & & & CRP & $(\mathrm{cm})$ & & \\
\hline & & & 80 & & & & 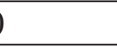 & & 00 & \\
\hline & Apical & Inter. & Apical & Inter. & & Apical & Inter. & Apical & Inter. & \\
\hline $5\left(8^{*}\right)$ & 445,9 & 448,0 & 439,4 & 433,1 & $441,6 a$ & 55,7 & 62,5 & 65,5 & 99,3 & $70,7 \mathrm{a}$ \\
\hline $6\left(9^{*}\right)$ & 571,6 & 451,2 & 556,3 & 453,0 & $508,0 \mathrm{a}$ & 32,7 & 47,7 & 62,4 & 59,8 & $50,6 \mathrm{~b}$ \\
\hline $8(11 *)$ & 229,0 & 302,9 & 356,9 & 307,5 & $299,0 \mathrm{~b}$ & 81,0 & 78,4 & 82,1 & 78,8 & $80,1 \mathrm{a}$ \\
\hline 4 & $415,5 \mathrm{~A}$ & $400,7 \mathrm{~A}$ & $450,9 \mathrm{~A}$ & $397,9 \mathrm{~A}$ & & $56,5 \mathrm{~A}$ & $62,9 \mathrm{~A}$ & $70,0 \mathrm{~A}$ & $79,3 \mathrm{~A}$ & \\
\hline VII & & $1 \mathrm{~A}$ & 424 & $37 \mathrm{~A}$ & & & 7B & & 7A & \\
\hline
\end{tabular}

Em que: (*)meses após a poda apical das mudas; $\mathrm{CV}$ = coeficiente de variação, em \%; Médias seguidas da mesma letra maiúscula na linha e minúscula na coluna não diferem entre si pelo teste de Tukey $(5 \%)$.

com médias 12,8 e 10,5, respectivamente (Tabela 2).

Ao contrário do ipê-roxo, Ribeiro et al. (2007) observaram maior número de folhas nas estacas apicais de quaresmeira (Tibouchina fothergillae Cogn.) na concentração de $812,5 \mathrm{mg} \mathrm{L}^{-1}$ de AIB, estimada pelo ponto de máxima com derivação da equação. Já, para o 
as características estudadas, exceto o número de folhas, sobre a qual houve interação entre tipo de miniestacas e aplicação de AIB.

As miniestacas apicais sem aplicação do regulador de crescimento, bem como mudas da oitava coleta de produção, aos onze meses, após a poda apical, apresentaram número de folhas por planta inferiores em relação aos demais tratamentos, enraizamento, os resultados são semelhantes aos encontrados para o ipê-roxo, em que não é necessária a aplicação de AIB.

Um fator importante a ser considerado durante o manejo do minijardim é a época de coleta das miniestacas, devendo ser coletadas no máximo vigor vegetativo da planta doadora de propágulos, uma vez que irá influenciar na formação de raízes e crescimento das mudas. A altura, diâmetro, área foliar, massa seca da parte aérea e do sistema radicular foram influenciadas apenas pela época de coleta. A altura apresentou maior média $(23,96$ $\mathrm{cm})$ na sexta coleta de produção, e menor na oitava $(12,07 \mathrm{~cm})$, aos nove e onze meses após a poda apical. A quinta coleta de brotação, aos oito meses após a poda apical proporcionou maior diâmetro das mudas, com média de 5,6 $\mathrm{mm}$. As mudas da oitava coleta de brotação, aos onze meses após a poda apical, apresentaram também as menores médias de área foliar, massa seca da parte aérea e do sistema radicular (Tabela 2).

$\mathrm{O}$ número e o comprimento de raízes adventícias primárias foram maiores com a aplicação de AIB. No entanto, é provável que essas raízes sejam mais finas, pois não houve variação em sua massa seca. Essas variáveis também foram influenciadas pela época de coleta, em que a quinta e oitava coleta, aos oito e onze meses após a poda apical, respectivamente, apresentaram maiores médias. O número de raízes adventícias primárias foi maior nas miniestacas intermediárias do que nas apicais (Tabela 2).

Apesar da aplicação de AIB não ter proporcionado maiores taxas de enraizamento, este influenciou positivamente no vigor das miniestacas, uma vez que as mudas apresentaram sistema radicular mais robusto, evidenciado pelo maior número e comprimento de raízes adventícias primárias. Esse comportamento se manteve desde a fase de enraizamento até a formação das mudas aos 120 dias. Entretanto, melhores resultados podem ser alcançados através de novos estudos no intuito de aumentar a taxa de enraizamento e qualidade da muda formada.

\section{CONCLUSÕES}

A propagação vegetativa por miniestaquia de minicepa seminal apresentou potencial para produção de mudas de ipê-roxo, independentemente da posição do propágulo e da aplicação de auxina. Entretanto, sugere-se que novos estudos sejam realizados para incrementar o percentual de enraizamento das miniestacas.

\section{AGRADECIMENTO}

Ao Conselho Nacional de Desenvolvimento Científico e Tecnológico (CNPq) pela concessão da bolsa de mestrado.

\section{REFERÊNCIAS BIBLIOGRÁFICAS}

ALFENAS A. C. et al. Clonagem e doenças do eucalipto.Viçosa, Universidade Federal de Viçosa. 2009. 2 ed. 442 p.

BOLLES JONES, E. W. Nutrition of Hevea brasiliensis I. Experimental methods. Journal Rubber Research International Malaya, v.14, 1954. p.183.

BORGES, S. R. et al. Enraizamento de Miniestacas de clones híbridos de Eucalyptus globulus. Revista Árvore, v.35, n.3, p.425-434, 2011.

CARVAlHO, P. E. R. Espécies Florestais Brasileiras: recomendações silviculturais, potencialidades e uso da madeira. Colombo: Embrapa. 1994. 640 p.

CARVALHO, P. E. R. Espécies florestais brasileiras. Colombo: EMBRAPA/CNPF. 2003. v.1. $1039 \mathrm{p}$.

CASTRO, W. H. Propagação vegetativa do jequitibá-rosa (Cariniana estrellensis (Raddi) Kuntze) e do pau-jacaré (Piptadenia gonoacantha (Mart.) Macbr.) por estaquia. Dissertação (Mestrado em Ciência Florestal), Universidade Federal de Viçosa-UFV, Viçosa-MG, 62p. 2011.

CUNHA, A. C. M. C. M. et al. Influência do estado nutricional de minicepas no enraizamento de miniestacas de eucalipto. Revista Árvore, v.33, n.4, p.607-615, 2009.

DIAS, P. C. et al. Propagação vegetativa de progênies de meios-irmãos de angico-vermelho (Anadenanthera macrocarpa (Benth) Brenan) por miniestaquia. Revista Árvore, Viçosa, v.36, n.3, p.389-399, 2012.

FACHINELLO J. C., HOFFMANN A., NACHTIGAL J. C. Propagação de plantas 
frutíferas. Embrapa Informação Tecnológica. Brasília. 2005. 221 p.

FERREIRA, D. A. et al. Influência da posição das miniestacas na qualidade de mudas de cedro australiano e no seu desempenho inicial no pósplantio. Ciência Florestal, Santa Maria, v. 22, n. 4, p. 715-723, 2012.

FIGUEIRÊDO, G. R. G. et al. Propagação da gravioleira por miniestaquia. Revista Brasileira de Fruticultura, v. 35, n. 3, p. 860-865, 2013.

FREITAS, T. P. Propagação de ipê-roxo (Handroanthus heptaphyllus Mattos) por miniestaquia. Dissertação (Mestrado em Produção Vegetal) - Campos dos Goytacazes-RJ, Universidade Estadual do Norte Fluminense Darcy Ribeiro UENF, 71p. 2012.

HARTMANN, H. T.; KESTER, D. E. Propagacion de plantas: principios y practicas. 4. ed. México: Continental. 1990. 760 p.

HERNÁNDEZ, W. et al. Propagação vegetativa do pau-jacaré (Piptadenia gonoacantha (Mart.) Macbr.) por estaquia. Revista Árvore, Viçosa, v.36, n.5, p.813-823, 2012.
MORAES, D. G. de. Enraizamento de miniestacas caulinares e foliares de cedro australiano e brotação de minicepas. Trabalho Monográfico - Agronomia - Campos dos Goytacazes - RJ, Universidade Estadual do Norte Fluminense UENF, 20p. 2008.

PAUlA, J. E.; ALVES, J. L. H. 897 Madeiras nativas do Brasil: anatomia, dendrologia, dendrometria, produção e uso. 1. ed. Porto Alegre: Cinco Continentes, 2007. 438p.

RIBEIRO, M. N. O. et al. Efeito do ácido indolbutírico sobre estacas apicais e medianas de quaresmeira (Tibouchina fothergillae Cogn.). Revista Brasileira de Horticultura Ornamental, v. 13, n.1, p. 73-78, 2007.

SILVA, R. L. et al. Propagação clonal de guanandi (Calophyllum brasiliense) por miniestaquia. Agronomía Costarricense, v. 34 n.1 p. 99-104, 2010.

TAIZ, L.; ZEIGER, E. Fisiologia vegetal. 5.ed. Porto Alegre: Artmed, 2013. 954p. ZIMMERMANN, F. J. P. Estatística aplicada à pesquisa agrícola. EMBRAPA Arroz e Feijão, 2004. 400 p. 